\title{
Análise do uso e ocupação do solo no interior baiano através das geotecnologias: estudo de caso no município de São Gabriel
}

\begin{abstract}
A ação antrópica vem causando mudanças significativas no uso e ocupação do solo, contribuindo para o desenvolvimento de muitos impactos ambientais negativo que causam a degradação dos recursos naturais, principalmente devido à agricultura e ao manejo inadequado do solo, como no município de São Gabriel. Deste modo, esse trabalho objetivou analisar a variação do uso e ocupação do solo entre os anos de 1987 a 2018 através das geotecnologias. Nesse sentido as classificações obtiveram precisões acima de $95 \%$ pelo método Kappa. De acordo com os resultados, a políticas de crédito rural realizada na década de 1960 na região influenciou diretamente na dinâmica espacial do município, uma vez que incentivou a supressão vegetal para o cultivo do feijão, milho e mamona. No ano de 1987 a área destinada a agricultura ocupava 52,8\% do município. Passados 31 anos e o fim da política de crédito rural, em 2018 ainda havia a permanência do manejo inadequado do solo. Além disso a área destinada a agricultura aumentou $13,07 \%$, porém houve a diminuição da produção ao longo dos anos com crescente área de solo exposto, correspondendo a $40 \%$ do município, que está em processo de degradação, destacando a perca de produtividade, assoreamento de corpos d'água e processos de erosões aceleradas, apontando ainda para algumas áreas em processo de desertificação e fragmentação do Bioma Caatinga.
\end{abstract}

Palavras-chave: Uso e ocupação do solo; Degradação dos recursos naturais; Geotecnologias.

\section{Analysis of land use and occupation in the interior of Bahia through geotechnologies: case study of the municipality of São Gabriel}

\begin{abstract}
Anthropic action has been causing significant changes in land use and occupation, contributing to the development of many negative environmental impacts that cause the degradation of natural resources mainly due to agriculture and inadequate soil management, as in the municipality of São Gabriel. Thus, this work aimed to analyze the variation of land use and occupation between the years 1987 to 2018 through geotechnologies. In this sense, the classifications obtained accuracy above $95 \%$ by the Kappa method. According to the results, the rural credit policies carried out in the 1960 s in the region directly influenced the spatial dynamics of the municipality, since it encouraged plant suppression for the cultivation of beans, corn and castor beans. In 1987, the agricultural area occupied $52.8 \%$ of the municipality. After 31 years and the end of the rural credit policy, in 2018 there was still the permanence of inadequate soil management. In addition, the area for agriculture increased $13.07 \%$, but there was a decrease in production over the years with an increasing area of exposed soil, corresponding to $40 \%$ of the municipality, which is in a process of degradation, highlighting the loss of productivity, silting of water bodies and accelerated erosion processes, also pointing to some areas in the process of desertification and fragmentation of the Caatinga Biome.
\end{abstract}

Keywords: Land use and occupation; Degradation of natural resources; Geotechnologies.

Topic: Tecnologia, Modelagem e Geoprocessamento

Reviewed anonymously in the process of blind peer.
Received: $11 / 08 / 2020$

Approved: 28/09/2020
Olávio Rocha Neto (iD)

Universidade Estadual da Paraíba, Brasil http://lattes.cnpq.br/9750143696204633 http://orcid.org/0000-0003-0152-5397

olavorochaneto12@gmail.com

José Fideles Filho

Universidade Estadual da Paraíba, Brasil http://lattes.cnpq.br/1994594710013360 fidelesfilho@uol.com.br

Gleyton Lopes Barboza Lacerda (iD

Universidade Federal Rural de Pernambuco, Brasil

http://lattes.cnpq.br/0941837243510458

http://orcid.org/0000-0002-1645-4387

gleytonlb@gmail.com

\begin{abstract}
Priscilla Gomes Barbosa (iD)
Universidade Estadual da Paraíba, Brasil http://lattes.cnpq.br/4823633249815596 http://orcid.org/0000-0002-3054-5680

priscillagomes.engambiental@gmail.com

Tássio Jordan Rodrigues Dantas da Silva Universidade Estadual da Paraíba, Brasil http://lattes.cnpq.br/1991160864996557 http://orcid.org/0000-0002-1708-5472 tassiojordan@hotmail.com
\end{abstract}

Referencing this:

ROCHA NETO, O.; FIDELES FILHO, J.; LACERDA, G. L. B.; BARBOSA, P G.; SILVA, T. J. R. D.. Análise do uso e ocupação do solo no interior baiano através das geotecnologias: estudo de caso no município de São Gabriel. Revista Ibero Americana de Ciências Ambientais, v.11, n.5, p.652-663, 2020. DOI: http://doi.org/10.6008/CBPC2179-

DOI: 10.6008/CBPC2179-6858.2020.005.0058 $\underline{6858.2020 .005 .0058}$ 


\section{INTRODUÇÃO}

O crescimento populacional, a urbanização, a falta de planejamento no uso e ocupação do solo, juntas com a falta de políticas públicas de preservação do meio ambiente vêm trazendo modificações no uso e ocupação do solo com sérios impactos ambientais em todo o mundo. Na bacia hidrográfica do Rio Ankobra na África a vegetação densa no ano de 1991 ocupava 40,4\% do espaço, em 2016 ocupava apenas 22,8\% de forma bastante fragmentada devido principalmente à urbanização e a mineração (OBODAl et al., 2019). Na província de Tongren na China entre os anos 2000 e 2016 houve uma diminuição na área da vegetação total e aumento de solo exposto devido à expansão urbana e construção de barragens (LIU et al., 2018). Entre os anos de 1980 e 2016 o sudoeste de Bangladesh, passou por significativas mudanças afetando os serviços ecossistêmicos (AKBER et al., 2018). Em Iguatu no Ceará foi averiguado o aumento de solo exposto devido a práticas de desmatamento e queimadas para fins agrícolas (SILVA et al., 2019).

Nessa perspectiva, a mudança no uso e a ocupação do solo de forma não planejada pode alterar e degradar o meio ambiente causando a impermeabilização da superfície do solo, além de assoreamento dos corpos d'água, contaminando águas superficiais e subterrâneas, provocando inundações, rebaixamento do lençol freático, perca da produtividade e processos de erosão acelerada (SÁNCHEZ, 2008; CALIJURI et al., 2019).

Alguns desses problemas ambientais já foram registrados no Município de São Gabriel, (SANTOS JUNIOR, 2004; ABREU, 2010) que faz parte da microrregião de Irecê na Bahia. Essa localidade passou por rápidas transformações em seus limites territoriais a partir da década de 50 , fomentada pelo financiamento e crédito para o plantio do feijão o que tornou a região conhecida pela sua produção do grão (PEREIRA et al., 2013; NEPOMUCENO, 2014).

Assim, para compreender e representar espacialmente a pressão e impacto das atividades antrópicas sobre os recursos naturais é fundamental o estudo do uso e ocupação do solo (LIMA et al., 2019). Estudo esse otimizado com as geotecnologias em destaque o sensoriamento remoto que fornece uma visão sinóptica e temporal de extensas áreas (FLORENZANO, 2007) comprovando seu potencial em trabalhos como Oliveira et al. (2018) na Paraíba, Xie et al. (2019) nos Estados Unidos Contíguos e Riad et al. (2020) na África.

Diante disso, o trabalho analisou a mudança no uso e ocupação do solo no município de São Gabriel, entre os anos de 1987 a 2018, com ênfase nas consequências ambientais da política do feijão, utilizando-se o auxílio das geotecnologias.

\section{METODOLOGIA}

\section{Localização da área}

O município de São Gabriel está localizado no estado da Bahia, na microrregião de Irecê, na região setentrional da Chapada Diamantina, com uma área aproximadamente de $1215 \mathrm{~km}^{2}$, entre as coordenadas geográficas $11^{\circ} 13^{\prime} 44^{\prime \prime}$ S e $41^{\circ} 54^{\prime} 43^{\prime \prime} \mathrm{O}$. Apresenta precipitação média anual de $600 \mathrm{~mm}$, clima semiárido e vegetação caatinga. 


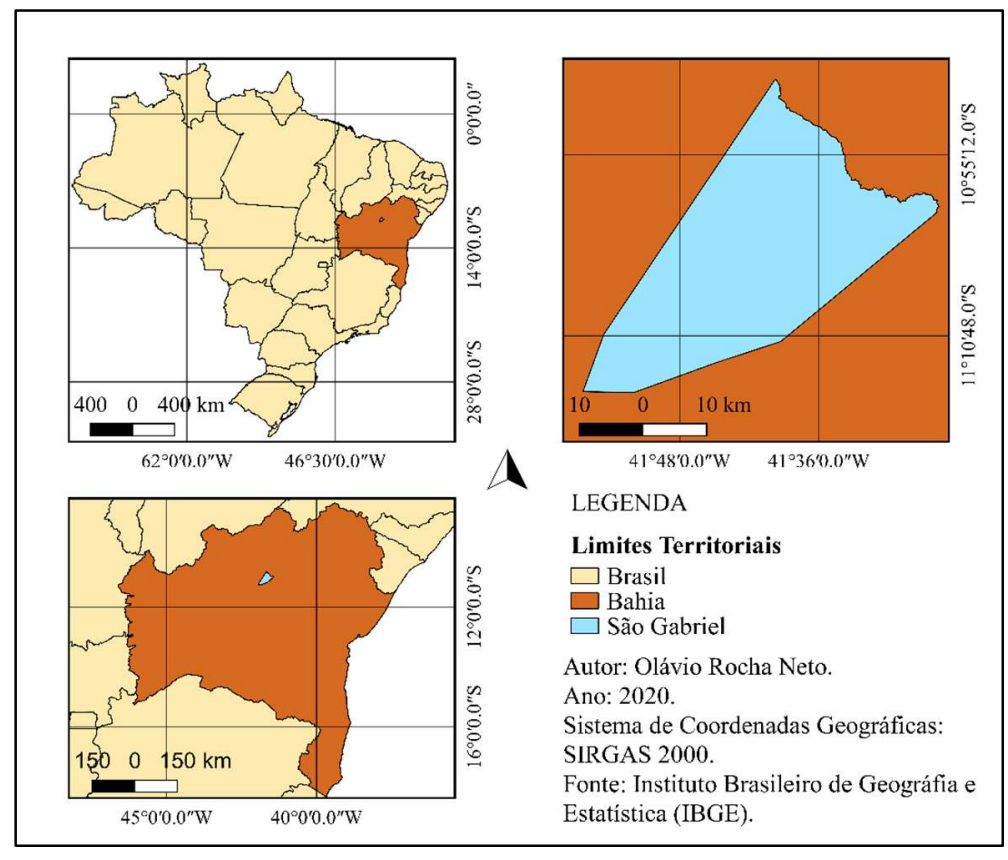

Figura 1: Localização do município de São Gabriel.

Em sua área nasce o Riacho Baixão de São Gabriel que corta parte do município, além disso parte é delimitado e banhado pelo Rio Jacaré, um dos afluentes do Rio São Francisco. Dessa forma a cidade está contida na Bacia hidrográfica do Rio Verde e Jacaré, que juntos contribuem com a Bacia Hidrográfica do Rio São Francisco. De acordo com o último Censo do IBGE, realizado em 2010 a população é de 18.427 habitantes, com a preponderância da agricultura familiar como fonte de renda (OLIVEIRA, 2015).

\section{Uso e Ocupação do solo}

Para confecção do trabalho necessitou-se de imagens do satélite Landsat 5 e 8, conforme a Tabela 1, adquiridas gratuitamente no site do Serviço Geológico dos Estados Unidos (USGS). Foram utilizados arquivos vetoriais do limite territorial do município, do estado da Bahia e do Brasil fornecidos pelo Instituto Brasileiro de Geografia e Estatística (IBGE). Além disso, foi feita uma consulta à literatura científica de estudos realizados no município e região.

Tabela 1: Descrição das imagens utilizadas no estudo.

\begin{tabular}{lll}
\hline Missão & Data & Órbita-Ponto \\
\hline Landsat 5 & $22 / 01 / 1987$ & $218-67$ \\
Landsat 5 & $12 / 04 / 1987$ & $218-68$ \\
Landsat 5 & $18 / 02 / 1997$ & $218-68$ \\
Landsat 5 & $18 / 02 / 1997$ & $218-67$ \\
Landsat 5 & $23 / 10 / 2010$ & $218-68$ \\
Landsat 5 & $23 / 10 / 2010$ & $218-67$ \\
Landsat 8 & $12 / 02 / 2018$ & $218-68$ \\
\hline
\end{tabular}

Fonte: USGS.

Para elaboração deste trabalho utilizou-se o software Qgis 2.18.21 e uma planilha eletrônica. Primeiramente as imagens Landsat foram pré-processadas, técnica com finalidade de calibrar a radiometria da imagem, atenuar os efeitos da atmosfera, remover ruídos, corrigir suas distorções geométricas, por meio do georreferenciamento e reamostragem (FLORENZANO, 2008). Essa etapa é elaborada com complemento 
Semi-Automatic Classification Plugin (SCP), seguido da reprojeção das coordenadas geográficas para SIRGAS 2000, processo também necessário nas imagens vetoriais da área em estudo.

O próximo passo consistiu na formação do mosaico entre as bandas das imagens do Landsat 5 do mesmo ano, afim de agrupar a real dimensão da área de estudo. Apenas no ano de 1987 as duas imagens possuem datas diferentes como observado na Tabela 1, assim foi considerando que não houve modificações significativas no uso e ocupação do solo devido ao pequeno intervalo de tempo. Logo após, foi elaborado o recorte da área de estudo em todas as imagens de satélite utilizando o arquivo vetorial do município como base.

Em seguida, foi calculado o NDVI na área de estudo em todas as imagens da Tabela 1, utilizando-se a Equação (1) descrita por Rouse et al. (1974), que consiste na diferença das reflectâncias das bandas de infravermelho próximo (NIR) e do vermelho (RED), dividida pela soma de ambas. Para o Landsat 5 a banda (NIR) é a 4 e a (RED) é a 3; no entanto, para o Landsat 8 essas bandas são respectivamente a 4 e 5.

$$
\mathrm{NDVI}=\frac{N I R-R}{N I R+R E D}
$$

Os valores de NDVI variam de -1 a +1 , sendo mais indicados para quantificar a vegetação. Quanto mais densa a vegetação, o NDVI terá valores próximos de 1, valores negativos refletem total ausência de vegetação como corpos d'água, enquanto os solos expostos apresentam valores próximos a 0 (MENESES et al., 2012).

De forma manual, averiguou-se as respectivas classes de uso e ocupação do solo e seus respectivos valores de NDVI, para a representação em mapas. Logo, foram adotados valores de referências sendo $-0,4$ referente a presença de água 0,15 , indicando a área de solo exposto representado na cor vermelha, que passa para a cor amarela entre os valores de 0,3 e 0,4 representando solos com baixa cobertura vegetal e chegando aos tons de verde em 0,7 demostrando áreas de vegetação densa. Quanto aos mapas foi escolhido a representação colorida linear, por facilitar o entendimento do leitor e conservar mais as características do terreno.

Logo após, foi elaborada a classificação manual supervisada com o complemento Semi-Automatic Classification Plugin (SCP) nos anos de 1987 e 2018. Sendo necessária mesclar as bandas 3, 4 e 5 do Landsat 5 e as 4,5 e 6 do Landsat 8 para obter a coloração falsa-cor com o padrão RGB das imagens. Nessa metodologia o pesquisador recolhe amostras das imagens dos espaços a serem estudados. Portanto, foi analisada as áreas de vegetação nativa, de agricultura cultivada, de agricultura com solo exposto, da urbanização, de corpos d'água, nuvens e afloramento rochosos.

Nessa etapa as imagens com valores de NDVI foram fundamentais para compreender a modificação da cobertura vegetal ao longo dos anos cruzando as informações com a classificação manual supervisionada, imagens do Google Earth e resultados de trabalhos científicos de alguns pesquisadores para validar as informações e complementar a análise do uso e ocupação do solo, além da visita em campo. Em seguida, foram escolhidas em torno de 70 a 80 amostras por imagem e executou-se o programa, que processa um arquivo vetorial da classificação e uma imagem para cada ano. Para a validação dos dados foi gerada a matriz de confusão e feita a classificação do índice Kappa com o SCP. 
Logo após com a tabela de atributos do Qgis obteve-se as áreas em $\mathrm{km}^{2}$ de cada classe do uso e ocupação do solo que foram exportados para a planilha eletrônica, calculado as porcentagens das áreas ocupadas e elaborado as tabelas com esses resultados. Os mapas de NDVI e de uso e ocupação do solo foram confeccionados no compositor de impressão do Qgis.

\section{RESULTADOS}

A classificação supervisionada mostrou-se eficiente, com coeficiente do índice Kappa de 98,78\% para o ano de 2018 e 97,64\% para o ano de 1987. Uma classificação muito boa, subsidiada principalmente pelos intervalos escolhidos que buscaram identificar a priori as seguintes classes: áreas com vegetação natural, representada desde a mata densa da caatinga à menos densa; a agrícola cultivada ou com solo exposto, em sua maioria representado todos os tipos de plantações, alguns pastos, o solo exposto e uma ínfima parte da urbanização; as nuvens e uma única classe representando corpos d'água, incluindo rio, riacho, pequenas lagoas, além de afloramento rochoso e sombras de árvores, de relevos ou nuvens.

Portanto, não foi identificado o tipo de cultura e os tipos de caatinga, e os lugares urbanizados devido a resolução de 30m das imagens. Santos et al. (2017) obtiveram um índice Kapa de 62\% devido a uma classificação mais detalhada com várias classes principalmente na vegetação a partir de imagens Landsat gerando maiores confusões na classificação, enquanto Riad et al. (2020) obtiveram coeficientes Kappa acima de $91 \%$ com menos intervalos de classes, abordando que a classificação média teve precisão de $95 \%$ utilizando em maioria imagens com resolução de $30 \mathrm{~m}$ e a menor precisão foi identificada em imagens com menor resolução do Landsat 1 apresentando algumas confusões nas classificações.

Em ambos os anos de estudo, foi apresentada confusões nas classificações, principalmente no intervalo das áreas cultivadas junto com sombras, afloramento rochoso e água. Oliveira et al. (2018) comentam que problemas assim estão relacionados a espaços com características espectrais similares, sugerindo trabalhar com imagens de alta resolução para otimizar a classificação e aumentar a quantidade de classes quando disponibilizadas nas imagens.

Tabela 2: Área do uso e ocupação do solo no Município de São Gabriel.

\begin{tabular}{lllll}
\hline Classificação do uso e ocupação do solo & \multicolumn{3}{c}{ Área \% } \\
\cline { 2 - 5 } & $\mathbf{1 9 8 7}$ & $\mathbf{2 0 1 8}$ & $\mathbf{1 9 8 7}$ & $\mathbf{2 0 1 8}$ \\
\hline Vegetação nativa & 563,2 & 485,9 & 46,3 & 40,0 \\
Agricultura área cultivada & 212 & 238,6 & 17,4 & 19,7 \\
Agricultura (Solo exposto com coloração branca) & 88,5 & 277,1 & 7,3 & 22,8 \\
Agricultura (Solo exposto com coloração vermelha ) & 340,9 & 209,0 & 28,1 & 17,2 \\
Nuvens & 1 & 0,1 & \\
Corpos d'água, afloramento rochoso, sombras de nuvens. & 9,6 & 3,9 & 0,8 & 0,3 \\
\hline
\end{tabular}

Está apresentado na Tabela 2, as informações das áreas do uso e ocupação do solo em 1987 e 2018. A Figura 2 representa o uso e ocupação do solo em 1987 e 2018. Em 22 de abril de 1987 o município de São Gabriel constava com $46,3 \%$ da sua área coberta por vegetação nativa, $52,8 \%$ da sua área destinada para fins agrícolas, $0,8 \%$ classificadas como corpos d'água, sombras de nuvens, afloramentos rochosos e $0,1 \%$ da área representado nuvens.

Esse ano é marcado com o declínio da produção de feijão, uma vez que segundo Nepomuceno (2014) 
os créditos agrícolas, o maior influenciador do desmatamento e produção agrícola, ocorreram entre a década de 50 e 90 . Pereira et al. (2013) relatam que foi na década de 60 que começaram as maiores supressões vegetais para dar início as produções agrícolas, assim o ano de 1987 demostra toda a modificação ocorrida no município com o financiamento da produção agrícola e seus impactos ambientais, como a extensa área destinada à produção agrícola.

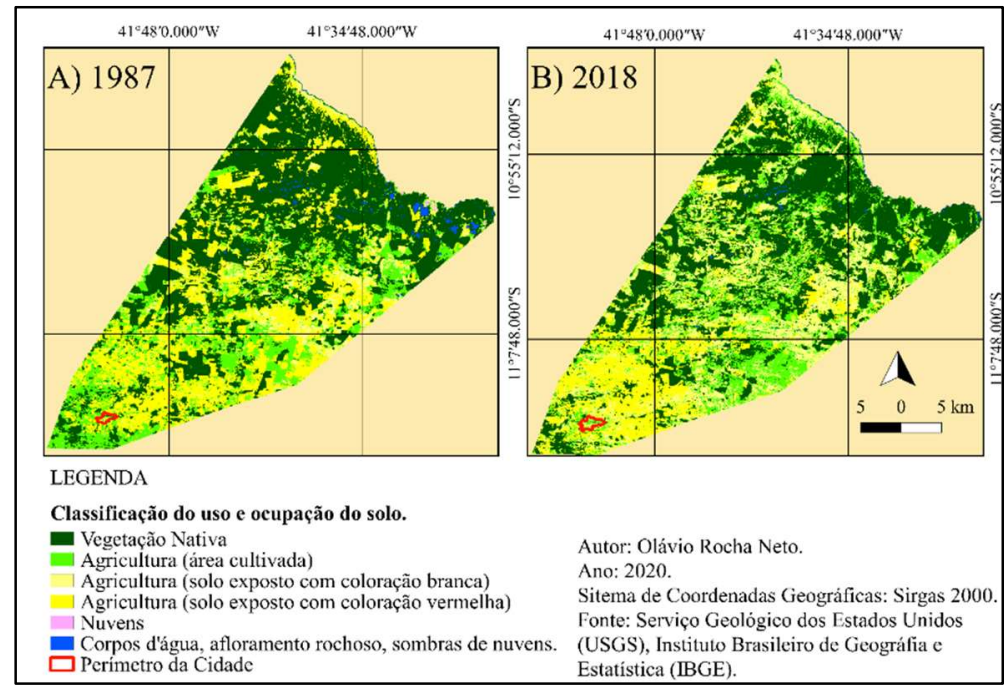

Figura 2: Uso e ocupação do solo do município de São Gabriel.

Nesse ano a vegetação possui maior predominância na região norte do município, enquanto as áreas mais próximas à cidade no Sudoeste foram destinadas às atividades agrícolas, provavelmente devido à maior facilitação de acessos, uma vez que o município de Irecê é popularmente conhecido como estrada do feijão, BA-052, principal fonte de escoamento da produção está localizados ao sul do município. Santos et al. (2017) também relataram a formação de áreas antropizadas próximas às Rodovias.

Ao total a área de produção agrícola é aproximadamente $641,4 \mathrm{~km}^{2}$. Essas por sua vez contêm três classes, a cultivada com apenas $17,44 \%$ da área total do município, a de solo exposto com coloração branca apresentado uma área de 7,3\% e outra com solo exposto com coloração avermelhada, abrangendo uma área de $28,1 \%$ em relação ao município. Os respectivos solos estão representados na Figura 3. Nesse intervalo ainda está inserido as áreas urbanizadas devido à semelhança espectral, porém com área total menor que $0,3 \%$ do município.
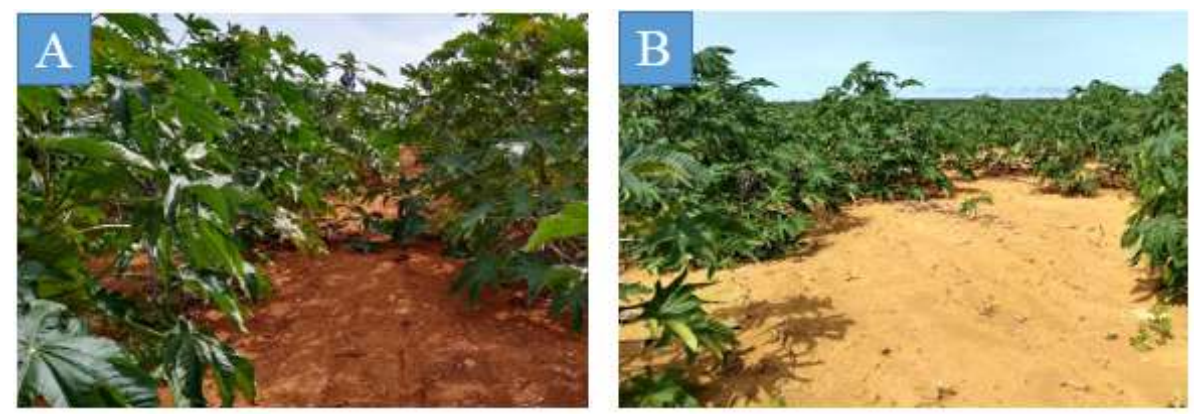

Figura 3: Solos característicos do município com coloração vermelha e branca utilizado para a monocultura da Mamona.

Mesmo sendo áreas destinadas a fins de agricultura, mais da metade se encontram com solo exposto. 
A agricultura na região nessa época do feijão acontecia com práticas não conservacionistas do solo (PEREIRA et al., 2013). Envolve a utilização de queimadas, aração mecanizada não planejada, a não reposição de nutrientes do solo, a não adaptação do cultivo de forma conservacionista ao relevo (SANTOS JUNIOR, 2010; NEPOMUCENO, 2014; OLIVEIRA, 2015). O solo era preparado para fins agrícolas no período da seca entre julho e outubro, seguido da semeadura no período chuvoso (OLIVEIRA, 2015) uma vez que a agricultura de predominância é a de sequeiro. Deste modo, de acordo com a data da Figura 2 representando o ano de 1987, pressupõe que as culturas deveriam estar no clímax, mas isso só é observado em $212 \mathrm{~km}^{2}$ dos 641,1 km² destinados à agricultura, percebendo o declínio da produção do campo nesse ano.

Na classificação em 1987, 9,6 km² do município foi identificado como área de afloramento rochoso, corpos d'água, sombras de nuvens representados pela cor azul. Foi escolhida somente uma classe para todas essas características devido à semelhança espectral, aumentando a qualidade dos dados. Portanto, em relação aos corpos d'água, esses se encontram em maior abundância na fronteira norte do município, devido ao Rio Jacaré, em contraponto, os afloramentos rochosos são mais incidentes no centro norte e as sombras das nuvens ou relevo estão em maior incidência na região nordeste da imagem.

Em 18 de fevereiro de 2018, 40,0 \% da área possuía vegetação nativa, 59,7\% da área era destinada a fins agrícolas e 0,3\% da área contém nuvens, sombras, afloramento rochoso e corpos d'água. Comparando as imagens da Figura 2, percebe-se que a área da vegetação nativa diminuiu aproximadamente $6 \%$ no ano de 2018, enquanto a área destinada a fins de agricultura aumentou 13,07 \%. A redução significativa da porcentagem da caatinga não aconteceu somente em um único espaço específico, mas em toda a antiga área da vegetação, como fica evidente na Figura 2, principalmente no centro do município, havendo uma fragmentação da vegetação.

Soares et al. (2017) em sua área de estudo, destacam o raleamento da caatinga, processo antrópico em que são retiradas algumas espécies arbustivas e arbóreas para proliferação da forrageira. Atividades também predominantes na comunidade rural local que utilizam em sua maioria de árvores nativas para a construção de cercas e abastecimento de fogões a lenha no interior do munícipio. Ações essas, que fragmentam ainda mais o bioma que já possui grandes perímetros de divisão com as áreas da agricultura intensificando o efeito de borda. De acordo com Lima et al. (2019) o efeito de borda influencia na diminuição da diversidade biológica e altera a estrutura das árvores.

Nessa perspectiva, a área agrícola cresceu em cima da vegetação. Em 2018, 238,6 km² (19,7\%) da área total do município estava cultivada, enquanto que em 1987 a área de solo exposto aumentou para 40\%, sendo $22,8 \%$ solo de cor vermelha e $17,2 \%$ de cor clara. A modificações dos solos com diferentes cores podem estar relacionadas com novos desmatamentos e plantações em novas áreas.

De acordo com os estudos e dados organizados por Oliveira (2015), a área cultivada de feijão, milho e mamona em 1997 somavam 282 km², já em 2007 somavam 218 km² e em 2012 foi reduzida para 175 km². No mesmo estudo foi constatado a diminuição da plantação e da produtividade por área do feijão e do milho ao longo dos anos, relatando o aumento na mamona. As culturas mencionadas, com exceção do feijão, ainda se encontram na liderança do cultivo e produção na agricultura municipal em 2015. 
Nesse âmbito, o solo destinado a agricultura expandiu-se nos últimos 31 anos, ocorrendo o aumento da área cultivada em relação à 1987, surgindo novas áreas irrigadas. Constatou-se a queda da produção nos últimos anos no sistema de cultivo predominante, podendo se afirmar que o aumento do solo cultivado não condiz a um aumento da produção agrícola, confirmando a perca da fertilidade do solo atrelados a impactos da instabilidade pluviométrica da região, uma vez que a produção do tri consórcio feijão, milho e mamona em décadas passadas sempre foi baseada no sistema de sequeiro. Logo, percebe-se que ao longo dos anos a maior parte da área destinada à agricultura prevaleceu com solo exposto, fato confirmado pela análise do NDVI em diferentes anos no município.

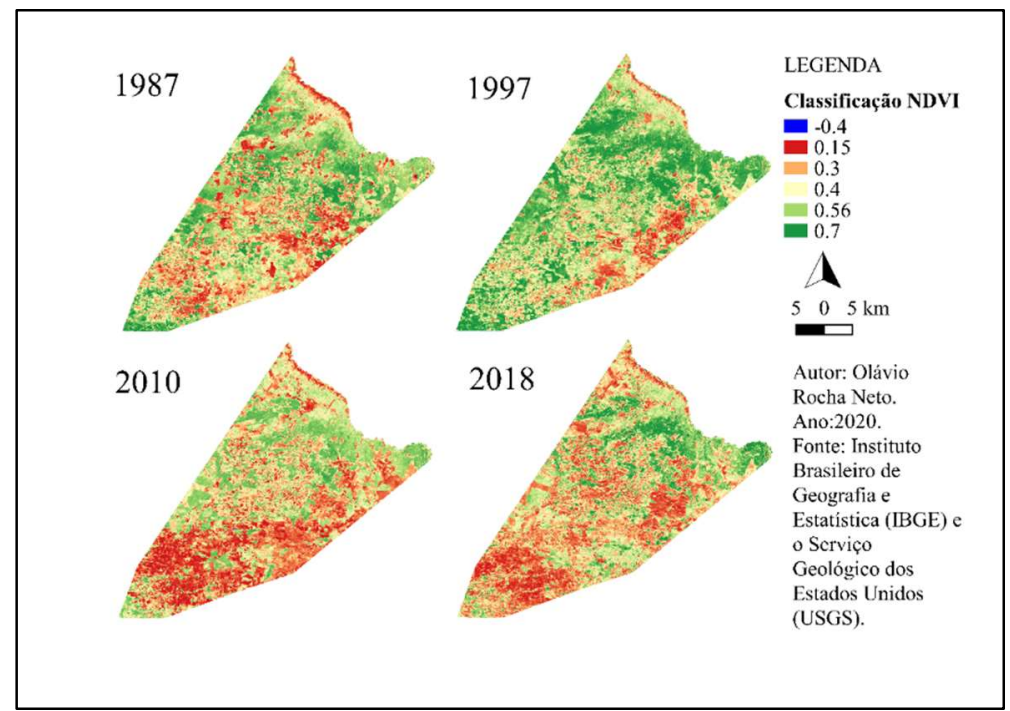

Figure 4: NDVI no Município de São Gabriel em diferentes anos.

A Figura 4, demonstra o uso e ocupação do solo em valores de NDVI nos anos de 1987, 1997, 2010 e 2018 em períodos chuvosos. Soares et al. (2017) em seu estudo consideraram valores de NDVI abaixo de 0,1 relacionados a corpos d'água, 0,1 e 0,2 com solo exposto, valores entre 0,3 e 0,5 como caatinga aberta e acima de 0,5 como caatinga densa. Rocha Neto (2019) analisou um município na mesma região, apontando que valores negativos são referentes às nuvens e corpos d'água, valores entre 0 e 0,3 ao solo exposto e urbanização, entre 0,3 e 0,6 à caatinga e agricultura e valores acima de 0,6 à caatinga densa.

A Figura 4, traz uma informação complementar à Figura 2, quanto a modificação do uso e ocupação do solo, explanando que entre os anos de 1987 e 1997 houve um aumento da cobertura vegetal em todo município. Essa alteração ocorre devido aos índices pluviométricos mais elevados, uma vez que valores elevados de NDVI no semiárido refletem a maiores precipitações devido ao aumento da atividade fotossintética (BARBOSA et al., 2017; AQUINO et al., 2018). Por conseguinte, essas novas áreas verdes em 1997, ano que não existia mais o crédito agrícola da política do feijão, podem ser atribuídas a regeneração da caatinga e áreas abandonadas de cultivo, além de áreas cultivadas corroborando com Aquino et al. (2018) que relatam sobre a contribuição da estiagem para o aumento do abandono de terras, elevando os valores de NDVI.

Já entre os anos de 1997, 2010 e 2018 houve um avanço e permanência da área de solo exposto, sendo prejudicial aos recursos naturais do município. Esse impacto no solo atrelado ao déficit hídrico, à falta 
de umidade do solo às altas temperaturas resultam no aumento do risco da degradação do solo, sendo a erosão acelerada o processo de degradação mais conhecido, podendo causar o empobrecimento do solo, produção excessiva de sedimentos e assoreamento de corpos d'água (ARAUJO et al., 2015; PAIVA et al., 2016; SILVA et al., 2019). Consequências ambientais já presentes no município e investigadas por Santos Junior (2004) no ano de 2004, continuaram crescendo sendo relatados por Abreu (2010), que averiguou parte do município em 2009 e, mais adiante um estudo elaborado em toda região por Nepomuceno (2014), ficando nítido o aumento da degradação ambiental no município e na região. Ambos pesquisadores destacaram ainda a supressão vegetal, a perca da produtividade, o rebaixamento do lençol freático, a compactação do solo e a degradação do riacho principal.

A Figura 5, evidencia situações comum no município, na região do Corta Asa que se localiza a 10km da cidade no sentido oeste. Pode se destacar a retirada de cobertura vegetal seguida da aração do solo para o cultivo (Figura 5C), e a erosão acelerada do solo no estágio de voçorocas junto com a monocultura do milho (Figura 5D).
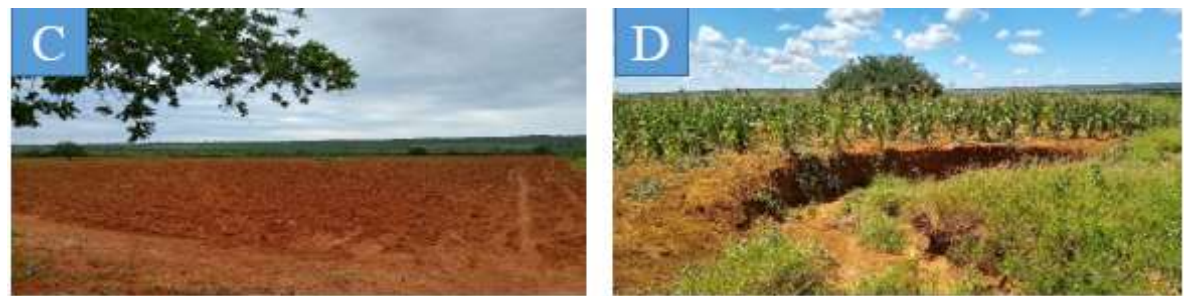

Figura 5: (C) solo exposto, (D) erosão acelerada e monocultura do milho.

O leito do Riacho Baixão de São Gabriel, junto com suas matas ciliares também são utilizadas para agricultura, apresentando o assoreamento do leito (Figura 6). A prática da remoção da mata ciliar para o cultivo é comum (Figura 6E), mesmo sendo em áreas com alta inclinação e protegidas por lei. Em outras áreas do Riacho, principalmente a área urbanizada, o leito do rio e as matas ciliares são utilizadas para criação de animais, apresentando um solo compactado e com menor retenção de água (Figura 6F).
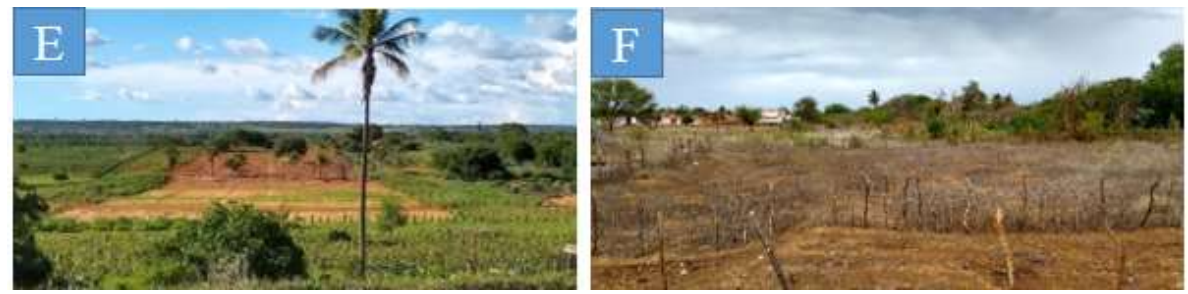

Figura 6: Leito do Riacho Baixão no ano de 2020 a montante da área urbana (E) e na área urbana (F);

Verifica-se que na Figura 7, ela traz algumas imagens da região do curralinho no extremo norte do município ao lado do Rio Jacaré. Esse apresenta algumas áreas em estágio de desertificação (Figura 7G e H), com solos desnudos e abandonados sujeitos a processos de erosão hídrica acelerada e eólica (Figura 7H e I). O Rio Jacaré (Figura 7J e k) mesmo sendo intermitente apresenta água em boa parte do ano, porém ele perdeu boa parte da mata ciliar e de seu volume de água. Observou-se, que algumas áreas do curralinho ainda possuem a vegetação preservada (Figura $7 \mathrm{~L}$ ). 

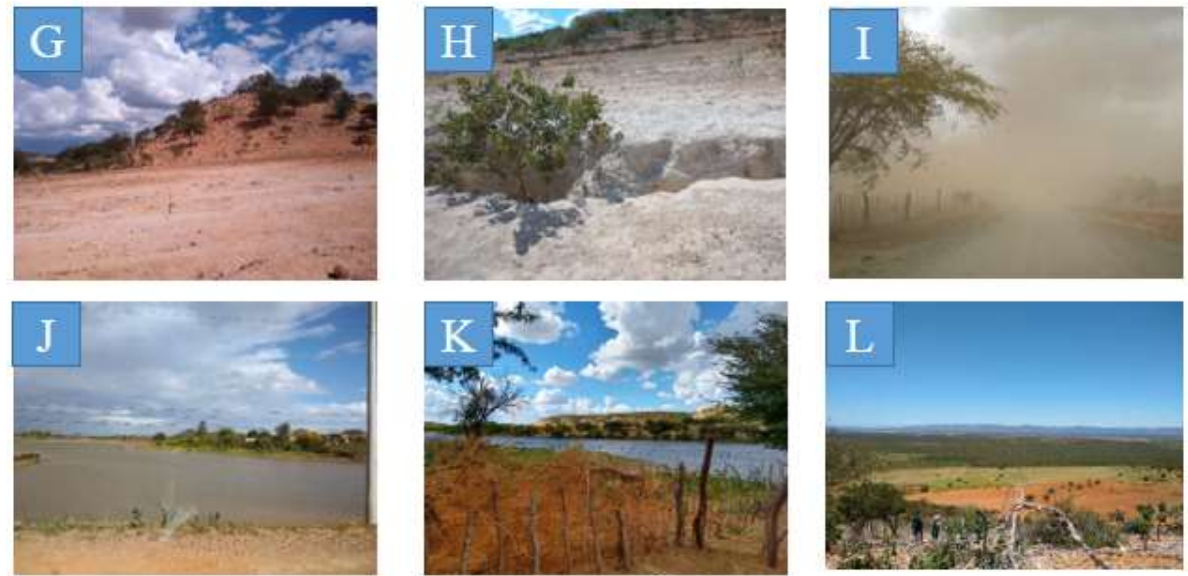

Figura 7: Imagens da Região do Curralinho no ano de 2019. Solo exposto (G), erosão hídrica (H), erosão eólica (I), trechos do Rio Jacaré (J e K), agricultura e vegetação (L).

Outra área visitada no estudo, foi a região do Esconde, localizada no centro norte do município (Figura 8), próximo ao povoado do Besouro. Foi identificada áreas de afloramento rochoso com várias fissuras que armazenam a água da chuva (Figura $8 \mathrm{M}$ e N), podendo ser áreas de recarga de aquíferos. $\mathrm{A}$ área apresenta alguns locais em recuperação natural da caatinga após o abandono da agricultura (Figura 80), processo comum em pequenas partes do município, além da divisa da vegetação e área agrícola ocasionando o efeito de borda (Figura 8P).
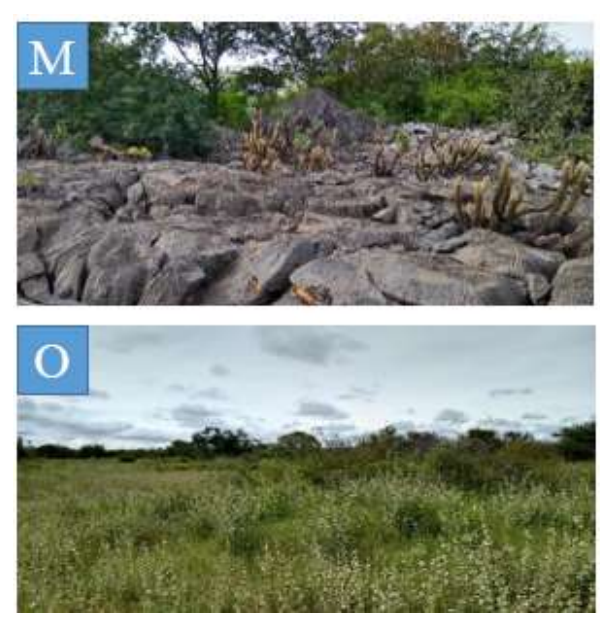

Figura 8: Imagens da Região do esconde no ano de 2020. Afloramento rochoso (M e N), recuperação natural (O) e área de borda $(P)$.

\section{CONCLUSÕES}

A metodologia da classificação supervisionada, mostrou resultados satisfatórios para a classificação do uso e ocupação do solo, porém as imagens com resoluções de $30 \mathrm{~m}$ não são adequadas para classificar o tipo de plantação, de vegetação e pequenas áreas urbanizadas.

A política do feijão foi a principal indutora para modificação do uso e ocupação do solo, trazendo grande supressão vegetal até o ano de 1987, e após 31 anos o sistema de manejo agrícola inadequado perdurou, junto com o aumento do solo exposto, chegando a $40 \%$ da área do município, apresentando estágio avançado de degradação, além da perca da produtividade agrícola.

Os grandes processos erosivos e os registros das imagens do Curralinho, não deixam dúvida o quanto 
algumas áreas estão em processos de desertificação. Além disso, diversos recursos hídricos foram degradados pela perda da mata ciliar.

A maior renda do município de São Gabriel é provinda da agricultura, assim é necessário uma reeducação agrícola e apoio técnico aos agricultores em geral para implantação de manejos conservacionistas do solo e água, respeitando as áreas de preservação permanente e buscando aproximarse do desenvolvimento sustentável. Dessa forma é necessária a presença de órgãos ambientais como o Instituto do Meio Ambiente e Recursos Hídricos (INEMA) para subsidiar e fiscalizar a região.

\section{REFERÊNCIAS}

ABREU, F. B.. Diagnostico dos Impáctos Ambientais na Microbacia do Riacho Baixão, São Sabrie/BA. Monografia (Bacharelado em Licenciatura em Geografia) - Universidade Estadual da Bahia, Jacobina, 2010.

AKBER, A.; KHAN, W. R.; ISLAM, A.; RAHMAN, M.; RAHMAN, $M$. R.. Impact of land use change on ecosystem services of southwest coastal Bangladesh. Journal of Land Use Science, v.13, n.3, p.238-250, 2018. DOI:

http://dx.doi.org/10.1080/1747423x.2018.1529832

AQUINO, D. N.; ROCHA NETO, O. C.; MOREIRA, M. A.; TEIXEIRA, A. S.; ANDRADE, E. M.. Use of remote sensing to identify areas at risk of degradation in the semi-arid region. Deodato do Nascimento Aquino: Revista Ciência Agronômica, Fortaleza, v.49, n.3, p.420-429, 2018. DOI: doi.org/10.5935/1806-6690.20180047

ARAUJO, G. H. S.; ALMEIDA, J. R.; GUERRA, A. J. T.. Gestão Ambiental de Áreas Degradadas. 11 ed. Rio de Janeiro: Bertrand Brasil, 2015.

BARBOSA, A. H. S.; CARVALHO, R. G.; CAMACHO, R. G. V.. Aplicação do NDVI para a Análise da Distribuição Espacial da Cobertura Vegetal na Região Serrana de Martins e Portalegre - Estado do Rio Grande do Norte. Geography Department University of Sao Paulo, v.33, p.128-143, 2017. DOI: http://dx.doi.org/10.11606/rdg.v33i0.128171

CALIJURI, M. C.; CUNHA, D. G. F.. Engenharia Ambiental: conceitos, tecnologias e gestão. 2 ed. Rio de Janeiro: Elsevier, 2019.

FLORENZANO, T. G.. Iniciação em Sensoriamento Remoto. 2. ed. São Paulo: Oficina de Textos, 2007.

FLORENZANO, T. G.. Geomorfologia: Conceitos e tecnologias atuais. São Paulo: Oficina de Textos, 2008.

LIMA, V. R. P.; SILVA-SEABRA, V.; ALBUQUERQUE-XAVIER, R.; CONCEIÇÃO-DORNELLAS, P.. Análise do Padrão Espacial do Uso e Cobertura do Solo e da Fragmentação e Conectividade da Vegetação no Semiárido do Nordeste Brasileiro: Bacias Dos Rios Taperoá e Alto Paraíba/PB. Revista de Estudios Andaluces, v.49, n.25, p.25-49, 2019. DOI: http://dx.doi.org/10.12795/rea.2019.i37

LIU, H.; ZHANG, Y.; ZHANG, X.. Monitoring vegetation coverage in Tongren from 2000 to 2016 based on Landsat7 ETM+ and Landsat8. Anais da Academia Brasileira de Ciências, v.90, n.3, p.2721-2730, 2018. Dol: http://dx.doi.org/10.1590/0001-3765201820170737

MENESES, P. R.; ALMEIDA, T.. Introdução ao processamento de Imagens de Sensoriamento Remoto. Brasília: Unb, 2012.

NEPOMUCENO, M. Q.. análise geossistêmica da região de Irecê-BA. Dissertação (Mestrado em Geografia) Universidade Federal da Bahia, Salvador, 2014.

OBODAI, J.; ADJEI, K. A.; ODAI, S. N.; LUMOR, M.. Land use/land cover dynamics using Landsat data in a gold mining basin-the Ankobra, Ghana. Remote Sensing Applications: Society and Environment, v.13, p.247-256, 2019. DOI: http://dx.doi.org/10.1016/j.rsase.2018.10.007

OLIVEIRA E. F.. Implicações da Pluriatividade na Produção do Espaço Agrário no Município de São Gabriel. Dissertação (Mestrado em Geografia) - Universidade Federal da Bahia, Salvador, 2015.

OLIVEIRA, W. S. N.; LIMA, A. S.; RIBEIRO, R. B. S.. Identificação de possíveis áreas salinizadas no perímetro irrigado de São Gonçalo utilizando o sensoriamento remoto. Revista Ibero-americana de Ciências Ambientais, v.9, n.4, p.362-378, 2018.

DOI: https://doi.org/10.6008/CBPC21796858.2018.004.0029

PAIVA, J. B. D.; PAIVA, E. M. C. D.. Hidrologia aplicada à gestão de pequenas bacias hidrográficas. Porto Alegre: Associação Brasileira de Recursos Hídricos (ABRH), 2016.

PEREIRA, J. P.; PEREIRA, L.. Terras dos Arcanjos: historiografia da cidade de São Gabriel/BA. 2 ed. Irecê: Print Fox, 2013.

RIAD, P.; GRAEFE, S.; HUSSEIN, H.; BUERKERT, A.. Landscape transformation processes in two large and two small cities in Egypt and Jordan over the last five decades using remote sensing data. Landscape and Urban Planning, v.197, p.1-11, 2020. DOI:

http://dx.doi.org/10.1016/j.landurbplan.2020.103766

ROCHA NETO, O.. Sensoriamento Remoto Aplicado a Análise da Mudança Temporal na Vegetação do Município de Canarana-BA. In: PRIMEIRO CONGRESSO INTERNACIONAL DE MEIO AMBIENTE E SOCIEDADE E TERCEIRO CONGRESSO INTERNACIONAL DA DIVERSIDADE DO SEMIÁRIDO, 1. Anais. Campina Grande: Realize, 2019.

ROUSE, J. W.; HASS, R. H.; SCHELL, J. A.; DEERING, D, W.. 
Monitoring vegetation systems in the great plains with

ERTS. NASA special publication, 1974.

SÁNCHEZ, L. E.. Avaliação de Impacto Ambiental: conceito e métodos. São Paulo: Oficina de Textos, 2008.

SANTOS JÚNIOR, M. O.. Degradação dos solos na microbacia do Riacho Baixão de São

Gabriel/BA. Monografia (Bacharelado em licenciatura em Geografia) - Universidade Estadual da Bahia, Campina Grande, 2004.

SANTOS, L. A. C.; BATISTA, A. C.; NEVES, C. O. M.; CARVALHO, E. V.; SANTOS, M. M.; GIONGO, M.. Análise multitemporal do uso e cobertura da terra em nove municípios do Sul do Tocantins, utilizando imagens Landsat. Revista Agro@mbiente, v.11, n.2, p.111-118, 2017. DOI: http://dx.doi.org/10.18227/1982-8470ragro.v11i2.3915
SILVA, J. L. B.; MOURA, G. B. A.; SILVA, Ê. F. F.; LOPES, P. M. O.; SILVA, T. T. F.; LINS, F. A. C.; SILVA, D. A. O.; ORTIZ, P. F. S.. Dinâmica espaço-temporal da cobertura vegetal de Caatinga por sensoriamento remoto em município do semiárido brasileiro. Revista Brasileira de Ciências Agrárias, v.14, n.4, p.1-10, 2019.DOI:

http://dx.doi.org/10.5039/agraria.v14i4a7128

SOARES, D. B.; NÓBREGA, R. S.; MOTA FILHO, F. O.. Mapeamento de solo exposto em área suscetível à desertificação em Pernambuco, Brasil. Revista Brasileira de Cartografia, Recife, v.9, n.69, p.1669-1676, 2017.

XIE, Y.; LARK, T. J.; BROWN, J. F.; GIBBS, H. K.. Mapping irrigated cropland extent across the conterminous United States at $30 \mathrm{~m}$ resolution using a semi-automatic training approach on Google Earth Engine. Isprs Journal of Photogrammetry and Remote Sensing, v.155, p.136-149, 2019. DOI: http://dx.doi.org/10.1016/j.isprsjprs.2019.07.005

A CBPC - Companhia Brasileira de Produção Científica (CNPJ: 11.221.422/0001-03) detém os direitos materiais desta publicação. Os direitos referem-se à publicação do trabalho em qualquer parte do mundo, incluindo os direitos às renovações, expansões e disseminações da contribuição, bem como outros direitos subsidiários. Todos os trabalhos publicados eletronicamente poderão posteriormente ser publicados em coletâneas impressas sob coordenação da Sustenere Publishing, da Companhia Brasileira de Produção Científica e seus parceiros autorizados. Os (as) autores (as) preservam os direitos autorais, mas não têm permissão para a publicação da contribuição em outro meio, impresso ou digital, em português ou em tradução. 